\title{
Japan broadly agrees to participation in SDI
}

\section{- Senate approval remains uncertain}

\section{- Japanese fear restrictions on commerce}

Tokyo \& Washington

JAPAN and the United States last week signed an agreement opening the way for Japanese companies and government research laboratories to join in the research phase of the Strategic Defense Initiative (SDI). But Japanese participation may be limited, both because of reluctance by Japanese industry to join in the project and efforts by the Congress to keep research dollars inside the United States.

It is more than two years since US Secretary of Defense Caspar Weinberger invited Japan to join the SDI research programme. Prime Minister Yasuhiro Nakasone, although keen for Japan to participate, proceeded very cautiously for fear of rousing protest from the opposition parties and the public. But apart from token resistance by scientists, opposition failed to materialize and, in September last year, Japan accepted Weinberger's invitation.

Since then, Foreign Ministry officials in Tokyo have been learning what is involved in negotiating contracts with the Pentagon, something new to Japan, while trying to secure terms favourable for participating Japanese industries. Many companies are interested in SDI research because of possible commercial spin-off, but fear that US secrecy and patent restrictions might rob them of any benefits gained by joining the programme.

Some industry fears will be allayed by the parts of the agreement made public. No restrictions will be placed on technology developed by Japanese companies before their involvement in SDI research and, although patents arising from the research will be held by the United States, companies may license the technology free of charge. But the technology may be used commercially only if it is unclassified and, according to a Foreign Ministry official who helped to negotiate the agreement, the Pentagon has "full authority to classify what it chooses".

Even if Japanese companies decide to join, they may find their way blocked by the US Congress. The House of Representatives has already passed an amendment to the defence authorization bill that would prohibit foreign participation in SDI research unless the work cannot be "competently performed in the United States" for the same money.

If the Senate adopts the same language, some participating governments fear that be rendered obsolete. their own SDI research agreements will

The timing of the Japanese agreement is significant, coming as it does on the heels of the Toshiba incident - the illegal export of milling machines to the Soviet Union by Toshiba Machine Co. (see Nature 328, 283; 1987). There were widespread reports of the case in the United States just as Congress was about to consider legislation liberalizing export controls. Congress will soon take the final steps to send the legislation to President Reagan, who has threatened to veto it.

The Toshiba case has brought on a bout of "Japan bashing" by the Congress, with sabre-rattling legislative sanctions and the public smashing of a Toshiba cassetteplayer with mallets. On the other hand, the Toshiba affair has allowed the Pentagon and the Nakasone administration to insist on increased Japanese-US collaboration in technology transfer, and a clampdown on COCOM violators.

Japan's ruling party intends to revise and/or renew the Foreign Exchange and Foreign Trade Control Law to tighten controls on high-technology exports to communist countries, and to treble the staff at the Ministry of International Trade and Industry (MITI) responsible for screening exports. In addition, MITI will draw up strict rules to protect military secrets from being given away by Japanese companies participating in SDI research. Under normal circumstances, such moves to strengthen government control of secrets would have raised howls of protest in Japan. In the wake of the Toshiba incident, however, they will probably pass unopposed.

But, considering the treatment of Toshiba by Congress, will Japanese companies still want to participate in SDI research? At least five or six companies are interested and have carried out indepth studies, says one of the Foreign Ministry negotiators. Even Toshiba's new president, Joichi Aoi, says his company still has ambitions to participate.

Other electronic producers holding technological advantages over the United States in such areas as gallium arsenide and laser diode research - the very areas of most interest to the Pentagon - still fear that their technology may be classified as secret if they join. Developments over Toshiba are doing nothing to ease their concern.

David Swinbanks \& Joseph Palca

\section{India builds big radiotelescope}

\section{New Delhi}

INDIAN astronomy is looking up after government approval for building what is likely to be the biggest radiotelescope of its kind in the world. It will observe metrewavelength radiation from the Universe, a region of the electromagnetic spectrum blotted out from telescopes of the Western world due to manmade radio interference.

The \$20-million Giant Metre Wavelength Radio Telescope (GMRT) will be built at Narayangav near Pune, which is about $200 \mathrm{~km}$ east of Bombay and free from pollution. The telescope, expected to be operational in 1992, will operate at frequencies of $38-150 \mathrm{MHz}$ and $325 \mathrm{MHz}$ and $610 \mathrm{MHz}$ and will be designed and built almost entirely by Indians.

"GMRT is a marriage of the world's two big radiotelescopes - the Very Large Array in New Mexico and the Arecibo radiotelescope at Puerto Rico - with the advantages of both", says Govind Swarup, director of the radioastronomy centre at the Tata Institute of Fundamental Research (TIFR) and the brains behind the project. The telescope will consist of 34 identical, steerable, $45-\mathrm{m}$ diameter parabolic dish antennae, forming a Y-shaped configuration spread over an area of $25 \mathrm{~km}^{2}$. To reduce weight and cost, the giant antennae will have 'seethrough' wire-mesh reflecting surfaces instead of solid steel.

According to Swarup, GMRT will be capable of resolving radio sources up to a few arc-seconds and will also provide high-resolution maps of galactic and extragalactic radio sources. GMRT will be open to all astronomers in India as well as to those elsewhere. Swarup expects that 10 per cent of the operational time of GMRT would be allocated for the best research proposals from astronomers from abroad.

GMRT will enable India to enter the high-technology astronomy race, but there is concern about the lack of a sufficient number of astronomers in India because very few Indian universities offer degrees in astronomy, which in turn is due to limited facilities in India for doing research in astronomy.

To solve the manpower shortage, a scheme has been launched jointly by TIFR and the University of Pune under which selected students will be given scholarships to work for master's degrees and doctorates in astronomy. It is also planned to advertise for scientific manpower in the United States where a number of Indians are studying astronomy or doing postdoctoral work.

K.S.Jayaraman 